\title{
Microbiota de la piel: el ecosistema cutáneo
}

Skin microbiota: The cutaneous ecosystem

\section{Luz Angélica Patiño1, Camilo Andrés Morales²}

1. Médica, residente de segundo año de Dermatología, Facultad de Medicina, Universidad CES, Medellín, Colombia; Centro Dermatológico Federico Lleras Acosta, E.S.E., Bogotá, D.C., Colombia.

2. Médico dermatólogo, Oficina de Docencia e Investigación, Centro Dermatológico Federico Lleras Acosta, E.S.E., Bogotá, D.C., Colombia; instructor, Facultad de Medicina, Universidad CES, Medellín, Colombia.

\section{Resumen}

En la superficie cutánea cohabitan bacterias, hongos y parásitos que, en condiciones normales, constituyen un complejo ecosistema en permanente interacción con el huésped. Este ecosistema participa activamente en la doble función protectora de la piel, como barrera física e inmunológica. Por lo tanto, cuando el equilibrio del ecosistema se trastorna, se generan consecuencias negativas que predisponen y causan la aparición de enfermedades.

En esta revisión se describen las características del ecosistema cutáneo, la composición de la microbiota de la piel, su variabilidad y las bases fisiológicas de sus principales interacciones.

PALABRAS CLAVE: microbiota, ecosistema, microbiología, flora cutánea.

\section{Summary}

In the skin surface cohabite bacteria, fungi and parasites; these microbes constitute a complex ecosystem which is in constant interaction with the host. This ecosystem is actively involved in the double protective function of the skin, as a physical and immunological barrier. When the balance of the ecosystem is disturbed, it has negative consequences and predisposes to disease.

In this review, we describe the characteristics of the ecosystem of the skin, the skin micriobiota composition, its variability and the physiological basis of their main interactions.

KEY WORDS: : microbiota, ecosystem, microbiology, skin flora.

\section{Correspondencia:}

Camilo Andrés Morales

Email:

camiderm@yahoo.com

Recibido: 24 de noviembre de 2012. Aceptado: 15 de febrero de 2013.

No se reportan conflictos de intereses.

\section{Introducción}

La superficie cutánea constituye un complejo ecosistema que sustenta diferentes nichos ecológicos. Su particular ambiente inhóspito, con un $\mathrm{pH}$ ácido y condiciones de humedad variables, entre otras características, podría dificultar la proliferación de microorganismos. Sin embargo, la microbiota de la piel, con una asombrosa capa- cidad de adaptación, ha evolucionado hasta convertirse en un importante aliado para la supervivencia humana a partir de una compleja selección natural de microorganismos residentes que evitan la colonización de otros agentes patógenos mientras trabajan en equipo con el sistema inmunitario de la piel.

Las alteraciones en la microbiota, como las que generan los cambios ambientales $\mathrm{u}$ ocupacionales, los 
hábitos de higiene inadecuados o la exposición a antibióticos, modifican el ecosistema y alteran la homeostasis cutánea, lo cual favorece la aparición de diferentes enfermedades ${ }^{1}$.

\section{Historia}

El término "flora" tiene una connotación botánica y hace alusión al nombre de la diosa latina de las flores y los jardines: Flora ${ }^{2}$. Por lo tanto, es un término inadecuado para referirse a las comunidades de microorganismos vivos residentes en un nicho ecológico determinado. El término adecuado y aceptado actualmente es microbiota ${ }^{3}$.

El interés por la microbiota se remonta a los inicios de la microbiología en los siglos XVIII y XIX, con la utilización de medios de cultivo y el perfeccionamiento del microscopio. Desde entonces, y hasta la actualidad, la identificación de la microbiota de la piel humana se ha basado en limitados métodos de aislamiento ${ }^{4}$. Uno de los trabajos clásicos sobre el tema, publicado en 1954, sentenció: “queda mucho más por aprender de la ecología bacteriana de la superficie de la piel que del control de esta”, con lo cual se estimuló el estudio de la microbiota cutánea siguiendo el modelo de los ecosistemas ${ }^{5}$. En 1964, María Marples propuso la teoría ecológica, haciendo una analogía entre las densas poblaciones de microorganismos que se encuentran alrededor de las raíces (rizosfera) y el folículo piloso en la piel ${ }^{6}$.

La posterior implementación de las técnicas de reacción en cadena de la polimerasa (PCR) y la secuenciación de los genes que codifican ARN ribosómicos 16S, presentes en todas las bacterias, generó la expansión del conocimiento necesaria para ampliar la visión del mundo microbiano que se tenía hasta entonces, y permitió establecer una nueva y más precisa clasificación filogenética de los microorganismos ${ }^{7}$.

\section{Generalidades}

Al igual que en otros ecosistemas, donde se pueden generar diferentes relaciones, tanto positivas como negativas, en el ecosistema cutáneo predominan la simbiosis (cualquier relación estable entre dos o más organismos de distintas especies), el comensalismo (relación beneficiosa para uno de los organismos e indiferente para el otro) y la competencia (lucha para conseguir los recursos necesarios para sobrevivir) entre los microorganismos, y entre estos y el huésped ${ }^{7,8}$. Tales interacciones permanecen en un equilibrio constante $y$, al ocurrir un cambio en cualquiera de las dos partes, un microorganismo normalmente residente puede convertirse en

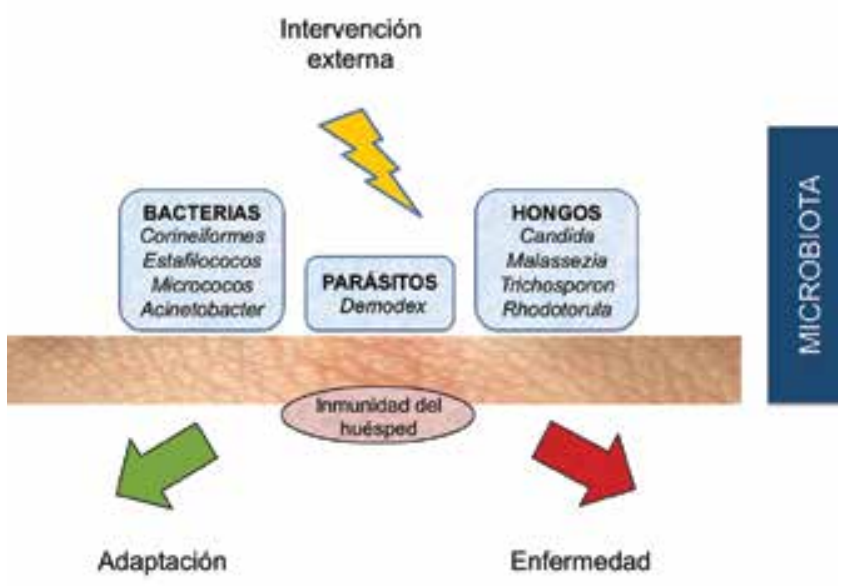

FIGURA 1. Homeostasis cutánea.

patógeno. Por ejemplo, Staphylococcus epidermidis es un comensal común, pero también es la causa más frecuente de infección adquirida en los hospitales y de colonización de dispositivos médicos, como catéteres y válvulas cardiacas ${ }^{8}$.

La microbiota de la piel humana es toda una colección de numerosas bacterias, hongos y ácaros que normalmente residen allí, con una relación de 1 a 10 con las células humanas ${ }^{9}$. A su vez, los biotopos que albergan a estos microorganismos son tan variados como lo es la topografía de la propia piel, y se considera que 9 de cada 10 células humanas presentan relaciones simbióticas con la microbiota; por lo tanto, las alteraciones en el ecosistema se traducen en enfermedades o propensión a estas (FIGURA 1).

La piel es un ambiente inhóspito que se caracteriza por extensas regiones desecadas, $\mathrm{pH}$ ácido, recambio continuo de sus células superficiales y producción de proteasas, lisozimas y péptidos antimicrobianos ${ }^{10}$. A pesar de estos mecanismos protectores, los microorganismos sobreviven y se extienden hasta los apéndices cutáneos $^{4}$ en una simbiosis en la que el huésped puede beneficiarse de diferentes maneras, entre ellas, de la protección contra las colonizaciones y posteriores infecciones por patógenos. Por ejemplo, Staphylococcus aureus es un patógeno común, y entre 20 y $30 \%$ de los individuos sanos son portadores nasales asintomáticos, aunque a partir de esta colonización también puede causar infecciones localizadas y sistémicas ${ }^{11}$. De igual forma, algunas cepas de $S$. epidermidis y Corynebacterium spp. pueden inhibir o revertir la colonización nasal de $S$. aureus, estableciendo una relación de mutualismo con el huésped al secretar modulinas solubles en fenol y proteasas de serina, moléculas con reconocida ac- 
tividad antimicrobiana, además de regular el sistema inmunitario para inducir la síntesis de péptidos antimicrobianos y, finalmente, producir la muerte de esta y otras bacterias patógenas ${ }^{1}$.

Otra importante interacción es la relacionada con el tipo de microbiota presente en las glándulas sudoríparas ecrinas y la atracción o rechazo por parte de algunos vectores, pues la mayoría de los compuestos volátiles del sudor a los que responden los mosquitos son de origen bacteriano ${ }^{12}$. Así, después de lavar los pies humanos con un jabón bactericida, se reduce de manera significativa la preferencia de las hembras de Anopheles gambiae, vector del paludismo, para picar en esta zona. Además, los individuos con mayor colonización por $S$. epidermidis también son más propensos a las picaduras de $A$. gambia $^{13}$. Teniendo en cuenta lo anterior, las potenciales aplicaciones médicas de estas interacciones apenas están por establecerse y podrían modificar los patrones de transmisión de numerosas enfermedades.

\section{Microbiota bacteriana}

Generalmente se divide en dos grupos, microbiota residente y microbiota transitoria ${ }^{1}$.

\section{Microbiota residente}

La microbiota residente está conformada por dos grupos relativamente fijos de bacterias que se encuentran habitualmente en la piel: un grupo mayor conformado por bacterias corineiformes y por estafilococos, y un grupo menor conformado por micrococos y Acinetobacter spp. ${ }^{14}$.

Las bacterias residentes a menudo se consideran comensales y mutualistas, lo que significa que no son dañinas y pueden representar un beneficio para el huésped. Sin embargo, algunas de ellas tienen un gran potencial patógeno, principalmente las del grupo Acinetobacter, como Escherichia coli, Proteus spp., Enterobacter spp., Klebsiella spp. y Pseudomonas spp. ${ }^{14}$.

\section{Microbiota transitoria}

Las bacterias transitorias no se establecen de forma permanente en la superficie de la piel, pero pueden persistir durante horas o días. Generalmente, no son patógenas en condiciones normales: con una higiene adecuada, una respuesta inmunitaria normal y una función de barrera cutánea preservada ${ }^{14,15}$. Está conformada principalmente por bacterias Gram positivas, como estreptococos del grupo A, S. aureus y cocos del género Neisseria ${ }^{14}$.

CORINEIFORMES. Son bacilos Gram positivos, aero- bios, no esporulados, de crecimiento lento, que se pueden dividir en dos grupos: lipofílicos y no lipofílicos. En el primero se incluyen Brevibacterium spp., Dermatobacter spp. y Propionibacterium spp., y en el segundo, Corynebacterium xerosis y Corynebacterium minutissimum $^{16}$. La mayoría son saprófitos que se aíslan de la piel, la mucosa oral y la vaginal, el conducto auditivo externo, las fosas nasales, la faringe y la mucosa intestinal $^{17}$.

Propionibacterium acnes es un bacilo Gram positivo, anaerobio facultativo, que produce ácido propiónico como subproducto metabólico, coloniza las glándulas sebáceas, obtiene energía de los ácidos grasos del sebo y es ocho veces más frecuente que las otras propionibacterias; su colonización se inicia poco tiempo después del nacimiento y se incrementa entre uno y tres años antes de la madurez sexual, especialmente en la cara $\mathrm{y}$ el tórax ${ }^{18}$. Aunque se relaciona con varias enfermedades dermatológicas, también posee efectos benéficos sobre el huésped al modular la respuesta inmunitaria y hacerla más eficaz ante determinados patógenos; produce bacteriocinas que protegen el nicho pilosebáceo de otros patógenos y, a cambio de esta protección, utiliza los nutrientes presentes en el sebo, desarrollando así una relación mutualista con el huésped ${ }^{10}$.

Corynebacterium xerosis hace parte de la microbiota normal de la piel y la orofaringe, pero puede ocasionar infecciones graves, especialmente en individuos inmunosuprimidos ${ }^{19}$.

La colonización de las glándulas sudoríparas apocrinas en la bóveda axilar, por parte de bacterias corineiformes y estafilococos, entre otros microorganismos, causa el mal olor del sudor humano en esta zona ${ }^{7}$.

ESTAFILOCOCOS Y MICROCOCOS. Son cocos Gram positivos, anaerobios facultativos. Una de las especies más importantes es $S$. aureus, que posee además un polisacárido (proteína A) específico y es considerado microbiota transitoria patógena. En estudios realizados con grandes poblaciones se ha encontrado que el $20 \%$ de los individuos nunca son colonizados por la bacteria, el $60 \%$ son portadores intermitentes y el $20 \%$ son colonizados persistentemente ${ }^{10}$.

Staphylococcus epidermidis es el microorganismo más frecuentemente aislado de la piel y conforma más del 90\% de la microbiota aerobia residente; posee un polisacárido B específico y solo ocasionalmente causa algún daño a los queratinocitos, produciendo péptidos tóxicos para otros microorganismos, como $S$. aureus y estreptococos del grupo $\mathrm{A}^{10}$. La epidermis permite el crecimiento de $S$. epidermidis, mientras que este le proporciona al huésped un nivel adicional de péptidos antibacterianos, como epidermina, epilancina K7, epilancina15X y Pep5, 
lo que constituye una perfecta relación de mutualismo huésped-bacteria ${ }^{20}$.

Otras especies aisladas con alguna frecuencia en la piel son S. hominis, S. capitis, S. cohnii, S. haemolyticus, S. saprophyticus, S. wameri, S. xilosus y S. simulans ${ }^{14}$.

\section{Microbiota fúngica}

Después de las bacterias, los hongos son el segundo grupo en importancia en la microbiota cutánea. Se han aislado diferentes especies de los géneros Candida, $M a$ lassezia, Trichosporon y Rhodotorula.

Candida albicans y C. glabrata se han considerado parte de la microbiota cutánea comensal en el tubo digestivo y el aparato urogenital, y más del $70 \%$ de los individuos sanos son portadores de $C$. albicans en la cavidad oral ${ }^{21}$; se puede comportar como un microorganismo oportunista en la piel, cambiando a su fase de micelio y aprovechando cambios locales, invade y desencadena la respuesta inmunológica. Su colonización comienza a temprana edad, apenas en el período posnatal, pues el recién nacido adquiere cepas procedentes de la madre ${ }^{22}$, mientras que otras especies son saprofitas del medio ambiente (suelo y vegetales). Los factores que permiten a $C$. albicans aumentar su proporción relativa como microbiota cutánea, son los que comprometen la inmunidad del huésped, principalmente la leucopenia y los tratamientos con esteroides, o que interfieren con la función de los linfocitos $\mathrm{T}$ (síndrome de inmunodeficiencia adquirida), además de la diabetes mellitus, que predispone a la infección probablemente debido al incremento en la producción de manoproteínas de superficie en presencia de altas concentraciones de glucosa ${ }^{7}$. Los trastornos de la mucosa asociados con enfermedad crónica, y sus tratamientos, pueden potenciar el proceso de invasión mediante la exposición de los sitios de unión de la cándida a la matriz extracelular ${ }^{21}$.

Malassezia spp. es una levadura lipofílica incapaz de sintetizar de novo ácidos grasos de $\mathrm{C}_{14}$ o $\mathrm{C} 16$ que, en presencia de ácido oleico, produce ácido azelaico, además de otros ácidos carboxílicos. Las especies más frecuentemente encontradas en la piel normal son $M$. sympodyalis, $M$. globosa y $M$. restricta ${ }^{23}$. Otras especies, como $M$. ovale, $M$. furfur y $M$. orbicularis, se aíslan con menor frecuencia y $M$. pachydermatis no hace parte de la microbiota normal en los humanos, pero es frecuente en los animales ${ }^{24}$.

$\mathrm{Su}$ aislamiento depende de la zona anatómica: en el tronco se ha identificado M. sympodyalis, M. globosa, $M$. slooffiae y $M$. furfur; en el conducto auditivo externo, $M$. restricta, $M$. sympodyalis y $M$. globosa, y a nivel de la piel cabelluda, $M$. sympodyalis, $M$. globosa, $M$. slooffiae, $M$. restricta y $M$. furfur ${ }^{25}$. Para poder actuar como comensal, la levadura utiliza mecanismos protectores, como un pigmento similar a la melanina que la hace menos sensible a especies reactivas de oxígeno ${ }^{26}$. Se estima que las diferentes especies de Malassezia constituyen entre el 53 y el $80 \%$ de la población total de los hongos en la piel humana, con mayor concentración en el pliegue retroauricular y en el sexo masculino ${ }^{7}$.

En cuanto a las diferencias según la localización anatómica, la información disponible es contradictoria; sin embargo, en un estudio reciente en el que se utilizaron métodos de aislamiento directos e indirectos, se informó que en los hombres predominan $M$. restricta en el rostro, y $M$. globosa y $M$. dermatitis en la parte superior del tronco, mientras que en la mujer se aíslan con mayor frecuencia $M$. globosa y $M$. sympodialis en la parte superior del tronco, con menor cantidad de especies en el rostro de las mujeres que en el tórax, lo que representa una relación inversa con Propionibacterium spp. y el estafilococo negativo para coagulasa, que se podría explicar por una competencia entre especies o por las diferencias en la composición del sebo en diferentes áreas ${ }^{27}$.

Trichosporon spp. está ampliamente distribuido en la naturaleza y puede ocasionalmente hacer parte de la microbiota de la piel, a partir del suelo y la madera en descomposición. Todas las especies de este género son capaces de asimilar carbohidratos y fuentes de carbón, y degradar la urea. La primera especie descrita fue $T$. beigelli, conocido como un hongo ambiental y saprófito, identificado como agente etiológico de la piedra blanca ${ }^{28}$ que también se puede aislar normalmente del tubo digestivo y las heces ${ }^{29}$.

Del género Rhodotorula, conformado por varias especies de levaduras, solamente $R$. mucilaginosa y $R$. glutinis son componentes habituales de la microbiota genital, gastrointestinal y ocular de algunos individuos sanos. Se han informado casos de onicomicosis, vaginitis y queratitis, además de infecciones profundas diseminadas que, generalmente, afectan a pacientes inmunosuprimidos ${ }^{30}$.

\section{Microbiota parasitaria}

Los ácaros Demodex folliculorum y D. brevis son ectoparásitos de la familia Demodicidae y se consideran parte de la microbiota normal ${ }^{31}$; el primero también recibe el nombre de "ácaro del folículo" por habitar en el interior del folículo piloso del huésped y es el que se aísla con mayor frecuencia en la piel 7 (FIGURA 2), en comparación con $D$. brevis, que predomina en las glándulas sebáceas y de las de Meibomio ${ }^{31}$. La localización más frecuente es la cara, particularmente la nariz, las mejillas, la frente, las sienes y la barbilla, pero también se ha encontrado en el borde libre de los párpados y los folículos de las 


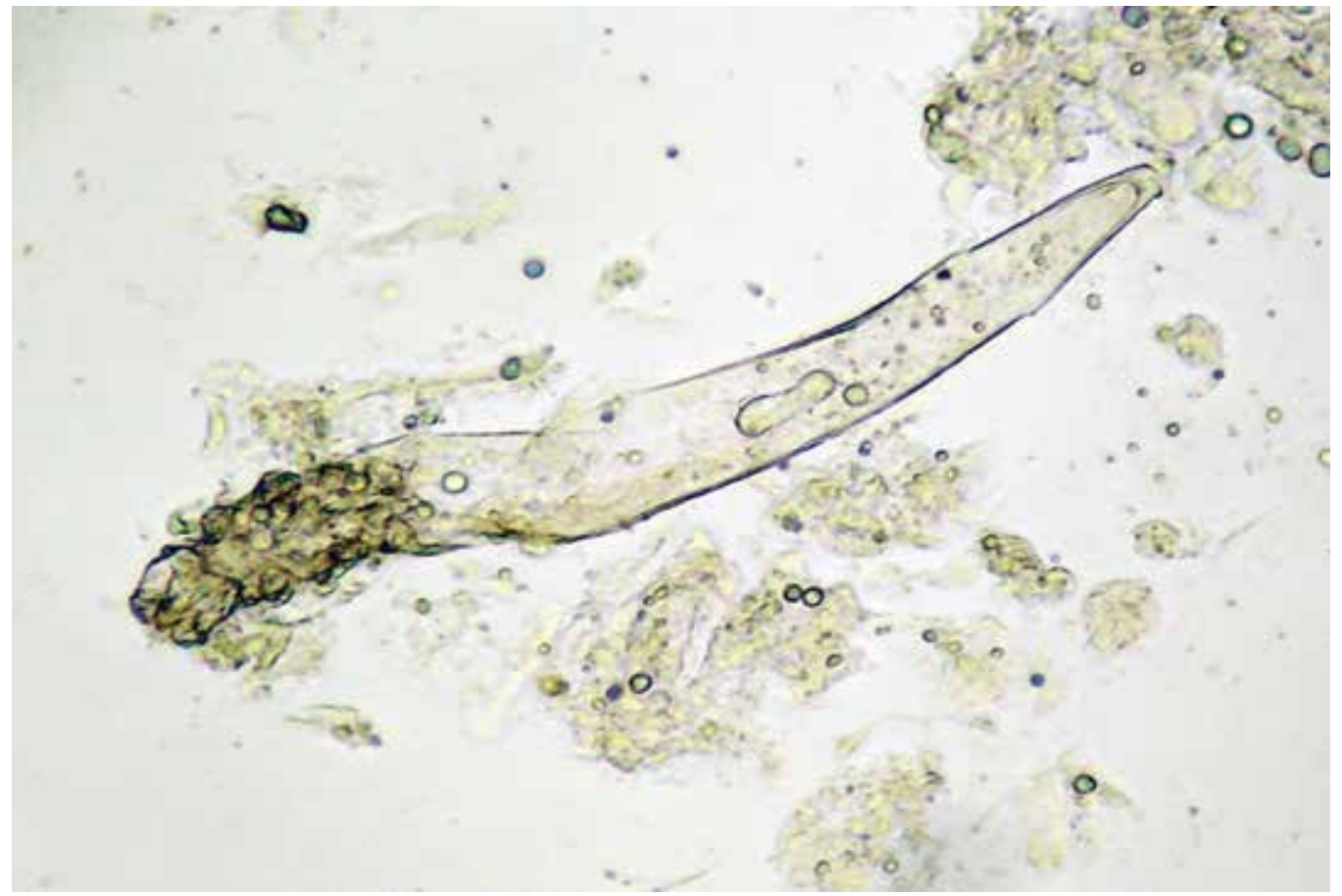

Figura 2. Demodex folliculorum. Montaje en $\mathrm{KOH}$ al $40 \%(10 X)$ pestañas. Demodex folliculorum puede alimentarse de las células epiteliales que recubren la unidad pilosebácea o, incluso, de otros microorganismos que habitan el mismo espacio, como P. acnes ${ }^{7}$.

Además de su papel en la microbiota, $D$. folliculorum y $D$. brevis se han relacionado con enfermedades como la demodicidosis y la rosácea, debido a su potencial capacidad para inducir hiperqueratinización folicular y una reacción inflamatoria de tipo cuerpo extraño o por hipersensibilidad retardada, además de actuar como vector de algunas bacterias que también pueden desencadenar variadas respuestas inflamatorias ${ }^{32,33}$.

\section{Microbiota cutánea e inmunidad del huésped}

La piel es una barrera física e inmunológica con complejos mecanismos de defensa que se pueden dividir en tres compartimentos funcionales. El primer compartimento es la defensa epitelial, que se caracteriza por la presencia de péptidos y proteínas antimicrobianas; el segundo es la inmunidad innata, encargada del reconocimiento de componentes microbianos por medio de receptores como los de tipo toll (Toll Like Receptor, TLR) con la subsecuente activación de vías de señalización que permiten la expresión de citocinas proinflamatorias e interferones; y el tercero es la inmunidad adaptativa, representada por las células presentadoras de antígenos, y los linfocitos $\mathrm{T}$ y $\mathrm{B}$ activados ${ }^{34}$.

Los queratinocitos, principales células de la epidermis, tienen un papel activo en la respuesta inmunitaria por medio de la producción de citocinas, quimiocinas, péptidos antimicrobianos y la expresión de receptores TLR. El proceso de producción de los péptidos antimicrobianos, que controlan el crecimiento microbiano en la superficie de la piel, se lleva a cabo en diferentes células de la piel (queratinocitos, células sebáceas, glándulas ecrinas y mastocitos) y en células circundantes como los neutrófilos y las células asesinas naturales (natural killers, NK) ${ }^{35}$, y está regulado por la síntesis de citocinas como IL-22 y por el reconocimiento de estructuras moleculares presentes en los microorganismos denominadas patrones moleculares asociados a patógenos (PathogenAssociated Molecular Patterns, PAMP) ${ }^{36}$. Los principales péptidos con actividad antimicrobiana en la piel son las catelicidinas, las defensinas beta (hBD), la proteína bactericida de aumento de permeabilidad (BPI), la lactoferrina, la lisozima, la dermacidina, las histonas, la psoriasina (S100A15) y la ribonucleotidasa (RNasa) $7^{37}$.

Las catelicidinas fueron los primeros péptidos antimicrobianos identificados en los mamíferos y su actividad antimicrobiana se ha comprobado en diferentes modelos animales. El principal péptido de esta familia en los humanos es la catelicidina LL-37, que tiene la capa- 
cidad de romper las membranas bacterianas y virales, además de actividad antifúngica ${ }^{37}$ y modular la apoptosis de los queratinocitos ${ }^{36}$; sin embargo, su actividad microbicida requiere de la activación proteolítica de su proteína precursora (hCAP18) por parte de diferentes enzimas epidérmicas ${ }^{38}$. Otros péptidos antimicrobianos también dependen de los queratinocitos para expresar su actividad microbicida, como la hBD-1, que requiere ser reducida por la tiorredoxina expresada en la epidermis $^{39}$ y las RNasas, cuya actividad es inhibida por la proteína inhibidora de RNasa, que es regulada por proteasas de serina del estrato córneo ${ }^{1,40}$.

Recientemente, se ha reconocido el papel de la quimiocina CXCL14 como péptido antimicrobiano de amplio espectro, debido a su actividad contra bacterias Gram positivas, E. coli y C. albicans. La CXCL14 se encuentra en menor cantidad en la piel de los pacientes con enfermedades inflamatorias, en comparación con individuos sanos, y podría ser fundamental en la respuesta inmunitaria durante las fases iniciales de la infección ${ }^{41}$.

Las bacterias comensales también pueden modular la respuesta inmunitaria en la piel al inducir la activación de los receptores TLR en los queratinocitos con sus ligandos (principalmente TLR2), así inhiben la respuesta inflamatoria como parte de una tolerancia inmunológica; caso contrario ocurre si estas bacterias invaden en mayor profundidad y son reconocidas por otras células del sistema inmunitario, como los macrófagos, lo que desencadena el proceso inflamatorio. El ácido lipoteicoico (LTA) producido por diferentes especies de estafilococos, que generalmente desencadena una respuesta inflamatoria en las células que no permanecen expuestas a la microbiota, como los macrófagos, los monocitos y los mastocitos, puede tener un efecto antiinflamatorio sobre el queratinocito suprimiendo las vías de señalización del TLR3 por medio de la inducción del factor 1 asociado al receptor de TNF (TRAF1) ${ }^{42}$.

Asimismo, algunas especies de Lactococcus, Streptococcus y Streptomyces producen factores con actividad bactericida contra otras bacterias, denominados bacteriocinas. Como ya se mencionó anteriormente, $S$. epidermidis produce epidermina, epilancina $\mathrm{K}_{7}$, epilancina $15 \mathrm{X}$ y Pep5, entre otros péptidos, conocidos como lantibióticos debido a su contenido de lantionina o metil-lantionina ${ }^{43}$.

Las glándulas sebáceas humanas también aportan a la barrera inmunológica de la piel la liberación de péptidos antimicrobianos, como catelicidinas, hBD e histonas, cuyos niveles de expresión son regulados positivamente en presencia de bacterias Gram positivas 3 344 Algunos de los ácidos grasos libres de cadenas mediana y larga (C8-C18) que ejercen actividad antibacteriana contra una amplia gama de bacterias Gram positivas, son producidos tanto por los sebocitos como por las lipasas de las bacterias de la microbiota normal, como $P$. acnes y $S$. epidermidis ${ }^{3}$.

Además de la actividad antimicrobiana directa, los ácidos grasos libres como el ácido láurico, el ácido palmítico y el ácido oleico, mejoran la inmunidad innata mediante la inducción de hBD-2 en los sebocitos ${ }^{45}$.

Las glándulas ecrinas también sintetizan péptidos antimicrobianos en la superficie epidérmica. La dermacidina es uno de estos péptidos, expresado como una pequeña proteína precursora en las glándulas sudoríparas ecrinas y secretado en el sudor, donde es activado; ejerce su acción por medio de la unión a un receptor no identificado de la membrana celular, generando una reducción en el ARN y la síntesis de proteínas ${ }^{46}$.

\section{Variabilidad de la microbiota cutánea}

Los hábitats de la piel tienden a ser muy diferentes entre segmentos corporales o estructuras anatómicas; sin embargo, son muy similares entre individuos de la misma edad y sexo, pues estos poseen propiedades físicas, químicas y fisiológicas comunes que facilitan la colonización de microorganismos con las mismas características $^{8,47}$.

\section{Variaciones topográficas}

\section{FOSAS NASALES Y PLIEGUES RETROAURICULARES}

Los microorganismos aislados con mayor frecuencia en individuos sanos son $P$. acnes, $S$. epidermidis y bacterias corineiformes, los cuales son relativamente estables en el tiempo ${ }^{48}$. En los pacientes hospitalizados, la microbiota de los orificios nasales difiere de la de los individuos sanos en el tipo y la diversidad de los microorganismos dominantes, con un aumento de $S$. aureus. En el pliegue retroauricular se ha encontrado mayor proporción de Malassezia spp. que en otros segmentos corporales ${ }^{8}$.

Cuando un individuo es colonizado por estafilococos, ésta se convierte en la cepa dominante y desplaza a los otros microorganismos, reduciendo la población normal de actinobacterias ${ }^{3}$. La colonización de las fosas nasales es un factor de riesgo para desarrollar posteriormente infecciones por $S$. aureus ${ }^{49}$. Existe, además, una interacción poco conocida por una interferencia bacteriana entre $S$. epidermidis y $S$. aureus: una proteasa de serina secretada por un subconjunto de $S$. epidermidis inhibe la formación de biopelículas y destruye las preexistentes, 
evitando la colonización nasal por S. aureus; esta interacción se correlaciona con la aúsencia de $S$. aureus en voluntarios sanos en los que predomina la colonización por S. epidermidis ${ }^{49}$.

\section{CAVIdAd ORAL}

La microbiota oral es de tipo mixto, con variaciones que dependen de las concentraciones de oxígeno, $\mathrm{pH}$ y azúcares, entre otras condiciones ${ }^{50}$. Las bacterias más frecuentemente aisladas son los estreptococos (30 al 60 $\%$ de la microbiota bacteriana), con predominio de $S$. viridans (S. salivarius, S. mitis, S. mutans y S. sanguis), además de especies no patógenas de Neisseria, Moraxella catarrhalis y $S$. epidermidis. La cantidad de bacterias anaerobias es máxima en el surco gingival, donde la concentración de oxígeno es menor de $0,5 \%{ }^{51}$; las bacterias supragingivales, generalmente, son anaerobias facultativas e incluyen estreptococos, Haemophilus spp., Leptotrichia spp., Actinomyces spp., Rothia spp., Corynebacterium spp. y Kingella spp., y las subgingivales son principalmente anaerobios obligados de los géneros Fusobacterium, Prevotella y Treponema ${ }^{52}$. Las bacterias que se adhieren a la superficie dental en forma permanente lo hacen por medio de diferentes polímeros de origen bacteriano, como dextranos y levanos, sintetizados a partir de hidratos de carbono de la dieta ${ }^{49}$. En la placa dentaria se encuentran $S$. mutans y $S$. sanguis; $S$. mitis se adhiere tanto a los dientes como a la mucosa y $S$. salivarius predomina en la mucosa lingual ${ }^{51}$.

También existen interacciones entre diferentes microorganismos que permiten que la microbiota residente normal predominante, en este caso estreptococos, inhiba el crecimiento de la microbiota patógena como $S$. aureus, S. pyogenes y Neisseria meningitidis, mecanismo que se inicia pocos días después del nacimiento ya que el recién nacido posee inicialmente en su cavidad oral una microbiota bacteriana muy parecida a la de la vagina materna $\mathrm{y}$, posteriormente, adquiere una microbiota similar a la de la boca del adulto cuidador, excepto las bacterias anaerobias que proliferan después de la erupción dentaria en el surco gingival ${ }^{51}$. Existen también alteraciones por el uso de antibióticos que favorecen el incremento de bacterias patógenas.

\section{SISTEMA GENITOURINARIO}

En este ecosistema, la microbiota normal puede modificar las condiciones del medio (factores como humedad y $\mathrm{pH}$ ) para favorecer su desarrollo e inhibir microorganismos patógenos ${ }^{53}$.

La microbiota normal está constituida tanto por las bacterias residentes en la piel (estreptococo alfa hemolítico, S. epidermidis, Propionibacterium spp. у Bacte- roides spp.) como por las de la mucosa (Micobacterium smegmatis, Bacteroides spp., Fusobacterium spp., Lactobacillus spp. y enterobacterias).

En la mujer predominan Lactobacillus spp., que acidifican el medio al sintetizar acido láctico ${ }^{54}$, producto del metabolismo del glucógeno, influenciados por el alto contenido de estrógenos; por esta razón, durante la gestación, a medida que progresa el embarazo, aumenta la densidad de Lactobacillus spp. y disminuye la de bacilos Gram negativos anaerobios y facultativos, dando como resultado un mecanismo que reduce el riesgo de bacteriemia grave durante el parto y el puerperio; su déficit se asocia a vaginosis bacteriana, que es un factor de riesgo para adquirir enfermedades de trasmisión sexual, incluyendo el VIH ${ }^{54}$.

En la etapa prepuberal predominan los microorganismos de origen cutáneo y perineal; pueden aislarse levaduras en escaso número, al igual que enterobacterias y bacilos Gram negativos anaerobios ${ }^{55}$. En la mujer posmenopáusica, por la disminución del estímulo hormonal, la microbiota de la vagina retorna al patrón que tenía en la infancia ${ }^{51}$. Algunas levaduras como $C$. albicans pueden formar parte de la microbiota vaginal normal, aunque eventualmente pueden proliferar y generar una vaginitis candidiásica, cuando se presentan cambios en el ecosistema ${ }^{56}$.

\section{ZONAS SEBORREICAS Y XERÓTICAS}

Propionibacterium spp. predominan en las zonas seborreicas, aunque la diversidad en los filotipos encontrados en estas zonas parece ser más baja. Los filotipos hacen relación a la clasificación taxonómica basada en las similitudes filogenéticas determinadas por análisis del ARN $16 S^{8}$.

Se han encontrado en la frente (seis filotipos), el pliegue retroauricular ( 15 filotipos), la espalda (17 filotipos) y el pliegue alar (18 filotipos), lo que sugiere que hay una selección de grupos específicos de organismos que pueden tolerar tales condiciones ${ }^{8,47}$. Otro factor que se debe tener en cuenta es que la colonización de otras zonas a partir de las unidades pilosebáceas es mayor que la que se ha descrito a partir de otras áreas, o del ambiente ${ }^{8}$.

Por otro lado, la piel con mayor diversidad en su microbiota corresponde a las zonas secas, con carácter mixto de los filos Actinobacteria, Proteobacteria, Firmicutes y Bacteroidetes. Estos sitios incluyen el antebrazo (44 filotipos), los glúteos y diferentes partes de la mano, donde abundan los microorganismos Gram negativos ${ }^{8}$.

\section{PALMAS Y PLANTAS}

La microbiota cutánea de las manos presenta una variabilidad especial pues posee más de 150 especies di- 


\begin{tabular}{lcc} 
Familia de & \multicolumn{2}{c}{ Diferencias entre sexos } \\
microorganismos & Hombres & Mujeres \\
\hline Propionibacterium & $37 \%$ más & --- \\
\hline Corynebacterium & $80 \%$ más & --- \\
\hline Enterobacterias & --- & $400 \%$ más \\
\hline Lactobacillaceae & --- & $340 \%$ más \\
\hline Moraxellaceae & --- & $180 \%$ más \\
\hline Pseudomonadaceae & --- & $180 \%$ más \\
\hline \hline
\end{tabular}

TABLA 1. Microorganismos comunes en las manos de hombres y mujeres y variación en su concentración según el sexo ${ }^{57}$.

ferentes. A pesar de la gran diversidad (más de 25 filos), predominan solo tres filos (Actinobacteria, Firmicutes y Proteobacterius) que representan el $94 \%$ de los microorganismos. Los géneros más abundantes son Propionibacterium (31,6\%), estreptococos (17,2\%), S. aureus $(8,3 \%)$, Corynebacterium (4,3\%) y Lactobacillus (3,1\%). La superficie de la palma tiene un gran número de taxones infrecuentes, que pueden ser microbiota bacteriana transitoria o residente ${ }^{57}$.

El uso de las manos tiene una influencia significativa en las comunidades bacterianas; la mano dominante de diferentes individuos tiene similares niveles de diversidad microbiana, al igual que las manos no dominantes entre sí. Sin embargo, la composición de las comunidades bacterianas en la mano dominante $\mathrm{y}$ la no dominante de un mismo individuo es significativamente diferente; comparten sólo el $17 \%$ de sus filotipos, en promedio ${ }^{57}$. También, hay mayor diversidad de especies en las manos de las mujeres comparadas con las de los hombres (TABLA 1), aunque en ambos sexos predominan bacterias de los mismos grupos: Propionibacterium spp., Streptococcaceae spp. y Staphylococcaceae spp. ${ }^{57}$.

La mayor diversidad de especies en las mujeres se explica por las diferencias en el pH, en la producción de sudor y sebo, la frecuencia de aplicación de cremas hidratantes o el uso de cosméticos, así como el grosor de la piel y la producción de hormonas ${ }^{57,58}$.

En la planta del pie predominan los estafilococos y, en los espacios interdigitales, Corynebacterium spp., micrococos y estafilococos, siendo uno de los sitios con mayor variación interpersonal ${ }^{47}$.

\section{Variaciones según sexo y edad}

Aunque el sexo no parece tener mucha influencia sobre la comunidad microbiana, el uso de maquillaje se ha asociado con el incremento de la diversidad bacteriana en la piel de la frente de algunas mujeres ${ }^{59}$. P. acnes es el microorganismo prevalente en la piel de la frente y se encuentra en menor proporción en las mujeres que utilizan maquillaje, hecho que se relaciona con una mayor colonización por estafilococos ${ }^{60}$.

Los cambios relacionados con la edad empiezan en el momento del parto, con la ruptura de las membranas, el paso del recién nacido por el canal vaginal, el posterior contacto del niño con la microbiota de la piel de la madre y de otras personas cercanas, y por los gérmenes del propio ambiente. La colonización inicial depende de la técnica del parto; si es vaginal, la microbiota cutánea se parecerá a la de la vagina de la madre, con predominio de Lactobacillus spp. y Prevotella spp., y si el parto es por cesárea, los niños albergarán comunidades bacterianas similares a las encontradas en la superficie de la piel, principalmente estafilococos, Corynebacterium spp. y Propionibacterium spp. ${ }^{61}$. Después de los tres meses de edad, la microbiota cutánea que puede encontrarse en un lactante es parecida a la del adulto, con algunos cambios como los que ocurren en la pubertad, con el incremento en la cantidad de bacterias lipofílicas ${ }^{62}$.

Al analizar las poblaciones microbianas más importantes por sexo, en función de la edad, en los grupos más jóvenes ( 1 a 3 y 4 a 6 meses) predominan los estreptococos y estafilococos, que representan hasta el $40 \%$ de la microbiota total de la piel, con otras 23 bacterias que componen el resto de la población total. A medida que la edad aumenta, asimismo lo hacen las especies de predominio bajo (<10 \%), mientras que los niveles de estreptococos y estafilococos disminuyen estadísticamente ${ }^{63}$.

\section{Interacciones entre la microbiota y la piel normal}

\section{Modificaciones fisiológicas}

Mientras que un $\mathrm{pH}$ ácido es perjudicial para bacterias, levaduras y dermatofitos patógenos, la elevación del $\mathrm{pH}$ estimula la actividad de las proteasas de serina y favorece el crecimiento de $S$. aureus y $S$. pyogenes, entre otras especies ${ }^{64}$. Un segundo factor modificador que tiene consecuencias negativas para varias funciones de la epidermis, es el estrés psicológico: mediante el aumento en los glucocorticoides endógenos se compromete la permeabilidad, la homeostasis de la barrera, la integridad del estrato córneo y la defensa antimicrobiana. Otra alteración importante es la inhibición de la síntesis de lípidos epidérmicos, que reduce la producción de cuerpos lamelares y su secreción, cuyo contenido de 


\begin{tabular}{lll}
\multicolumn{1}{r}{ Enfermedad } & \multicolumn{2}{c}{$\begin{array}{c}\text { Microorganismos } \\
\text { Disminución }\end{array}$} \\
$\begin{array}{l}\text { Psoriasis } \\
\text { Propionibacterium acnes } \\
\text { Estafilococos }\end{array}$ & $\begin{array}{l}\text { Candida albicans } \\
\text { Malassezia furfur }\end{array}$ \\
Acné & --- & $\begin{array}{l}\text { Propionibacterium acnes } \\
\text { Staphylococcus epidermidis }\end{array}$ \\
Rosácea & --- & Demodex folliculorum \\
\hline Dermatitis atópica & --- & Staphylococcus aureus \\
Dermatitis seborreica & --- & Malassezia globosa \\
\end{tabular}

TABLA 2. Alteraciones en la microbiota y relación con algunas enfermedades dermatológicas.

péptidos antimicrobianos, como hBD-2, catelicidinas y LL-37, también se disminuye ${ }^{65}$.

Entre las funciones del estrato córneo está el servir de barrera, tanto física como química, y por medio de sus lípidos, en particular los ácidos grasos libres y la esfingosina, ejerce una potente actividad contra bacterias, levaduras y virus ${ }^{66}$. Los cambios extremos repentinos en la humedad cutánea producen alteraciones significativas en la permeabilidad de la barrera, y las situaciones que aceleran la pérdida transcutánea de agua favorecen la entrada de antígenos y microorganismos patógenos ${ }^{64}$. La estrecha relación entre la permeabilidad y la función antimicrobiana se ha demostrado con el evidente aumento en la expresión de péptidos antimicrobianos después de la alteración de la barrera ${ }^{3}$.

\section{Modificaciones patológicas}

La eliminación de $S$. epidermidis debido al uso irracional de antibióticos, puede resultar perjudicial para el huésped porque se suprime gran cantidad de péptidos antimicrobianos bacterianos, lo que permite que agentes patógenos potenciales colonicen la piel con mayor eficacia; además, sin bacterias cebadoras para el sistema inmunitario, el huésped puede ser menos eficiente en su papel de vigilancia ante la infección ${ }^{67}$.

Otro cambio que ocurre con frecuencia se debe al uso de jabones y antisépticos en las manos, pues diferentes especies de bacterias se modifican dependiendo de la frecuencia del lavado de manos; en particular, las bacterias pertenecientes a los taxones Propionibacterium, Neisseria, Burkholderiales y Pasteurellaceae son relativamente más abundantes cuando el tiempo transcurrido desde el último lavado es mayor de cuatro horas, mientras que otras bacterias de los grupos Staphylococcaceae, Streptococcaceae y Lactobacillaceae presentan el patrón opuesto y son relativamente más abundantes en las manos recientemente lavadas. Aunque el lavado de manos altera la composición, no afecta las concentraciones globales de diversidad bacteriana, ni elimina la mayoría de los taxones de bacterias que se encuentran en la superficie de la piel ${ }^{57}$.

Existe una asociación entre el aumento de la humedad y del $\mathrm{pH}$, el uso de productos oclusivos y la colonización por bacilos Gram negativos y bacterias corineformes, incrementándose 10.000 veces el número de bacterias, además de un mayor aislamiento de hongos ${ }^{57}$. Es así como los cambios en las condiciones atmosféricas, como la disminución de la humedad y la temperatura, favorecen el crecimiento de la microbiota bacteriana normal, en contraste con la microbiota patógena, especialmente de $S$. aureus ${ }^{14}$.

Medicamentos como los retinoides modifican la microbiota cutánea al disminuir la producción de sebo, reducir el recuento de Propionibacterium spp. e incrementar el de $S$. aureus ${ }^{12}$. Los corticoides, dependiendo de la dosis, la potencia y el tiempo de uso, también pueden incrementar la colonización por microbiota patógena al suprimir la actividad del sistema inmunitario ${ }^{14}$. Los antibióticos tópicos pueden erradicar la microbiota residente e inducir resistencia bacteriana; así, por ejemplo, la aplicación de neomicina en las axilas inicialmente produce disminución de la colonización bacteriana, especialmente de corineiformes, pero posteriormente incrementa las bacterias Gram negativas ${ }^{12}$.

\section{Relación de la microbiota con algunas dermatosis}

Algunas enfermedades dermatológicas que no se consideran infecciosas, como la psoriasis, el acné, la rosácea y la dermatitis atópica, se relacionan con alteraciones en la composición de la micriobiota (TABLA 2) y con cambios en la respuesta inmunitaria del huésped que 
favorecen la inflamación crónica, entre otros mecanismos fisiopatológicos ${ }^{1}$.

En la psoriasis, enfermedad asociada con patrones anormales de diferenciación y crecimiento de los queratinocitos, hay disminución de $P$. acnes en la piel afectada. Por otro lado, cuando se presentan infecciones por estreptococos y otras bacterias, se empeoran algunas de sus manifestaciones clínicas, como es el caso de la psoriasis en gotas $^{10}$. C. albicans y $M$. furfur también se asocian con el desarrollo de lesiones, y la tasa de colonización por parte de $M$. restricta y $M$. furfur es el doble en pacientes con psoriasis en comparación con controles sanos, donde la especie más frecuente es $M$. globos $a^{68}$. También, se ha reportado que los pacientes con psoriasis tienen mayores concentraciones epidérmicas de LL-37 y hBD-2 en comparación con los pacientes con dermatitis atópica, lo cual se correlaciona con una mayor actividad antimicrobiana contra S. aureus ${ }^{69}$. Asimismo, se ha informado menor número de los géneros estafilococo y Propionibacterium spp. en los pacientes con psoriasis, en comparación con los controles sanos ${ }^{70}$.

La densidad de P. acnes se correlaciona positivamente con la tasa de secreción de sebo, y su mayor densidad corresponde con los mismos sitios de presentación del acné; sin embargo, aún se debate si la colonización por $P$. acnes es un evento etiológico primario o secundario. La cantidad de $P$. acnes cultivados a partir de la piel de pacientes con acné y sin él, no siempre se correlaciona con la existencia de la enfermedad o con su gravedad, y después del tratamiento, la mejoría no siempre coincide con una reducción en el número de colonias de $P$. $a_{c n e s^{71}}$. Los pacientes que sufren lesiones de acné podrían tener un incremento en la expresión de receptores epidérmicos TLR2 y 4, variaciones en la microbiota del folículo piloso y el conducto sebáceo, y una alteración en la producción de péptidos antimicrobianos, particularmente hBD, que protegen la unidad pilosebácea de la invasión microbiana e influencian la actividad de mediadores inflamatorios como lipasas, neuroamidasas, fosfatasas y proteasas $^{72}$.

En la rosácea, la infestación de la piel facial por el ácaro Demodex spp. puede contribuir a empeorar los síntomas de la enfermedad ${ }^{32}$. Los pacientes con rosácea tienen un incremento en la expresión de receptores TLR2 y mayores niveles del péptido antimicrobiano catelicidina en la piel de la cara que los controles, y estas catelicidinas favorecen un ambiente proinflamatorio ${ }^{1,73}$. La presencia de Demodex spp. en los folículos sebáceos podría inducir catelicidinas en la piel circundante, como parte de la respuesta inmunitaria innata frente al invasor, y contribuir así a la formación de eritema, pápulas y pústulas ${ }^{32}$.

En la dermatitis atópica, el $S$. aureus es un factor agra- vante. Entre el 80 y el $100 \%$ de los pacientes con enfermedad no tratada son colonizados por $S$. aureus ${ }^{74}$ y en la piel afectada las concentraciones de esta bacteria son mayores. Los orificios nasales se han identificado como un depósito de $S$. aureus, desde donde puede colonizar el resto de la piel y agravar la dermatitis atópica ${ }^{75}$. En estos casos, la deficiencia de esfingosina, dermacidina, hBD y catelicidina puede contribuir al aumento en la frecuencia de piodermitis ${ }^{76}$. Por otro lado, aunque no existen diferencias entre las especies de Malassezia que colonizan a los pacientes con dermatitis atópica en comparación con los individuos sanos, se han identificado genotipos de $M$. globosa y $M$. restricta que difieren de los que se encuentran en la población sana y que podrían tener un papel específico en la fisiopatogenia de la enfermedad ${ }^{77}$.

Se ha informado una correlación numérica entre los aislamientos de Malassezia spp. y la extensión de la dermatitis seborreica ${ }^{78}$, con cambios en la composición del sebo, asociados a la presencia de $M$. globosa y M. restricta, principalmente, reducción en la proporción de ácidos grasos, con predominio de ácidos grasos insaturados y liberación de metabolitos de ácidos grasos libres como ácido oleico. Estos metabolitos, luego de penetrar en las capas superiores de la piel, favorecen la hiperproliferación y la inflamación. Sin embargo, existen otros factores independientes de la levadura que se pueden relacionar con la extensión y gravedad de esta enfermedad ${ }^{78}$.

Algunas especies de Malassezia también se han relacionado con otras enfermedades, como agente causal en pitiriasis versicolor, foliculitis y fungemias, y como factor asociado en dermatitis seborreica, psoriasis, dermatitis atópica y pustulosis neonatal, entre otras ${ }^{25}$.

\section{Conclusión}

El ecosistema cutáneo y sus diversas interacciones son principios básicos que permiten comprender de manera integral la fisiología de la piel humana, la patogenia de algunas de las principales enfermedades dermatológicas y las consecuencias de cualquier intervención terapéutica.

\section{AgRADECIMIENTOS}

A Zulma Lorena Alvarado por la fotografía de la FIGURA 2.

\section{Referencias}

1. Gallo RL, Nakatsuji T. Microbial symbiosis with the innate immune defense system of the skin. J Invest Dermatol. 2011;131:1974-80.

2. Navarro FA. Glosario dermatológico de dudas inglés-español $\left(1^{\mathrm{a}}\right.$ parte): A-F. Actas Dermosifiliogr. 1999;90:327-38. 
3. Prats G. Los microbios y la enfermedad. En: Prats G. Microbiología clínica. Primera edición. Madrid: Editorial Médica Panamericana; 2006. p. 1-14.

4. Kong HH, Segre JA. Skin microbiome: Looking back to move forward. J Invest Dermatol. 2012;13:933-9.

5. Kligman AM, Leyden JJ, McGinley KJ. Bacteriology. J Invest Dermatol. 1976;67:160-8.

6. Marples MJ. Life on the human skin. Sci Am. 1969;220:108-15.

7. Fredricks DN. Microbial ecology of human skin in health and disease. J Invest Dermatol Symp Proc. 2001;6:167-9.

8. Grice EA, Segre JA. The skin microbiome. Nat Rev Microbiol. 2011;9:244-53.

9. Zhao L. Genomics: The tale of our other genome. Nature. 2010;465:879-80.

10. Kong HH. Skin microbiome: Genomics-based insights into the diversity and role of skin microbes. Trends Mol Med. 2011;17:320-8.

11. Cogen AL, Nizet V, Gallo RL. Skin microbiota: A source of disease or defence? Br J Dermatol. 2008;158:442-55.

12. Verhulst NO, Qiu YT, Beijleveld H, Maliepaard C, Knights D, Schulz S. Composition of human skin microbiota affects attractiveness to malaria mosquitoes. PLoS One. 2011;6:e28991.

13. De Jong R, Knols BG. Selection of biting sites on man by two malaria mosquito species. Experientia. 1995;51:80-4.

14. Roth RR, James WD. Microbiology of the skin: Resident flora, ecology, infection. J Am Acad Dermatol. 1989;20:367-90.

15. Reid G, Younes JA, van der Mei HC, Gloor GB, Knight R, Busscher HJ. Microbiota restoration: Natural and supplemented recovery of human microbial communities. Nat Rev Microbiol. 2011;9:27-38.

16. Hoffjan S, Stemmler S. On the role of the epidermal differentiation complex in ichthyosis vulgaris, atopic dermatitis and psoriasis. $\mathrm{Br}$ J Dermatol. 2007;157:441-9.

17. Gambichler T, Boms S, Stucker M, Kreuter A, Moussa G, Sand $\mathrm{M}$, et al. Epidermal thickness assessed by optical coherence tomography and routine histology: Preliminary results of method comparison. J Eur Acad Dermatol Venereol. 2006;20:791-5.

18. Mourelatos K, Eady EA, Cunliffe WJ, Clark SM, Cove JH. Temporal changes in sebum excretion and propionibacterial colonization in preadolescent children with and without acne. $\mathrm{Br} J$ Dermatol. 2007;156:22-31.

19. Pessanha B, Farb A, Lwin T, Lloyd B, Virmani R. Infectious endocarditis due to Corynebacterium xerosis. Cardiovasc Pathol. 2003;12:98-101.

20. Bierbaum G, Götz F, Peschel A, Kupke T, van de Kamp M, Sahl HG. The biosynthesis of the lantibiotics epidermin, gallidermin, Pep5 and epilancin K7. Antonie van Leeuwenhoek.1996;69:119-27.

21. Wächtler B, Citiulo F, Jablonowski N, Förster S, Dalle F, Schaller $\mathrm{M}$, et al. Candida albicans-epithelial interactions: Dissecting the roles of active penetration, induced endocytosis and host factors on the infection process. PLoS One. 2012;7:e36952.

22. Waggoner-Fountain LA, Walker MW, Hollis RJ, Pfaller MA, Ferguson JE 2nd, Wenzel RP, et al. Vertical and horizontal transmission of unique Candida species to premature newborns. Clin Infect Dis. 1996;22:803-8.

23. Ashbee HR. Update on the genus Malassezia. Med Mycol. 2007;45:287-303.

24. Prohic A, Kasumagic-Halilovic E. Identification of Malassezia pachydermatis from healthy and diseased human skin. Med Arh. 2009,63:317-9.
25. Hernández FH, Javier L, Tovar M, Mora EB, López AA. Especies de Malassezia asociadas a diversas dermatosis y a piel sana en población mexicana. Rev Iberoam Micol. 2003;52:141-4.

26. Gaitanis G, Chasapi V, Velegraki A. Novel application of the masson-fontana stain for demonstrating Malassezia species melanin-like pigment production in vitro and in clinical specimens. J Clin Microbiol. 2005;43:4147-51.

27. Akaza N, Akamatsu H, Sasaki Y, Takeoka S, Kishi M, Mizutani H, et al. Cutaneous Malassezia microbiota of healthy subjects differ by sex, body part and season. J Dermatol. 2010;7:786-92.

28. Chagas-Neto TC, Chaves GM, Colombo AL. Update on the genusTrichosporon. Mycopathologia. 2008;166:121-32.

29. Biasoli MS, Carlson D, Chiganer GJ, Parodi R, Greca A, Tosello ME, et al. Systemic infection caused by Trichosporon asahii in a patient with liver transplant. Med Mycol. 2008;46:719-23.

30. Shinde RS, Mantur BG, Patil G, Parande MV, Parande AM. Meningitis due to Rhodotorula glutinis in an HIV infected patient. Indian J Med Microbiol. 2008;26:375-7.

31. de Rojas M, Riazzo C, Callejón R, Guevara D, Cutillas C. Morphobiometrical and molecular study of two populations of Demodex folliculorum from humans. Parasitol Res. 2012;110:227-33.

32. Kligman AM, Christensen MS. Demodex folliculorum: Requirements for understanding its role in human skin disease. J Invest Dermatol. 2011;131:8-10.

33. Lacey N, Kavanagh K, Tseng SC. Under the lash: Demodex mites in human diseases. Biochem (Lond). 2009;31:2-6.

34. Meyer T, Stockfleth E, Christophers E. Immune response profiles in human skin. Br J Dermatol. 2007;157:1-7.

35. Schauber J, Gallo RL. Antimicrobial peptides and the skin immune defense system J Allergy Clin Immunol. 2008;122:261-6.

36. Chamorro CI, Weber G, Grönberg A, Pivarcsi A, Stahle M. The human antimicrobial peptide LL-37 suppresses apoptosis in keratinocytes. J Invest Dermatol. 2009;129:937-44.

37. Krishna S, Miller LS. Innate and adaptive immune responses against Staphylococcus aureus skin infections. Semin Immunopathol. 2012;34:261-80.

38. Yamasaki K, Schauber J, Coda A, Lin H, Dorschner RA, Schechter NM, et al. Kallikrein-mediated proteolysis regulates the antimicrobial effects of cathelicidins in skin. FASEB J. 2006;20:2068-80.

39. Schroeder BO, Wu Z, Nuding S, Groscurth S, Marcinowski M, Beisner J, et al. Reduction of disulphide bonds unmasks potent antimicrobial activity of human beta-defensin 1. Nature. 2011;469:419-23.

40. Abtin A, Eckhart L, Gläser R, Gmeiner R, Mildner M, Tschachler $\mathrm{E}$, et al. The antimicrobial heterodimer $\mathrm{S} 100 \mathrm{~A} 8 / \mathrm{S} 100 \mathrm{~A} 9$ (calprotectin) is upregulated by bacterial flagellin in human epidermal keratinocytes. J Invest Dermatol. 2010;130:2423-30.

41. Maerki C, Meuter S, Liebi M, Mühlemann K, Frederick MJ, Yawalkar $\mathrm{N}$, et al. Potent and broad-spectrum antimicrobial ac tivity of CXCL14 suggests an immediate role in skin infections. J Immunol. 2009;182:507-14.

42. Lai Y, Di Nardo A, Nakatsuji T, Leichtle A, Yang Y, Cogen AL, et al. Commensal bacteria regulate Toll-like receptor 3-dependent inflammation after skin injury. Nat Med. 2009;15:1377-82.

43. Bastos MC, Ceotto H, Coelho ML, Nascimento JS. Staphylococcal antimicrobial peptides: Relevant properties and potential biotechnological applications. Curr Pharm Biotechnol. 2009;10:38-41. 
44. Lee DY, Yamasaki K, Rudsil J, Zouboulis CC, Park GT, Yang JM, et al. Sebocytes express functional cathelicidin antimicrobial peptides and can act to kill Propionibacterium acnes. J Invest Dermatol. 2008;128:1863-6.

45. Nakatsuji T, Kao MC, Fang JY, Zouboulis CC, Zhang L, Gallo RL, et al. Antimicrobial property of lauric acid against Propionibacterium acnes: Its therapeutic potential for inflammatory acne vulgaris. J Invest Dermatol. 2009;129:2480-8.

46. Del Rosso JQ, Levin J. Clinical relevance of maintaining the structural and functional integrity of the stratum corneum: Why is it important to you? J Drugs Dermatol. 2011;10:S5-12.

47. Grice EA, Kong HH, Conlan S, Deming CB, Davis J, Young AC, et al. Topographical and temporal diversity of the human skin microbiome. Science. 2009;324:1190-2.

48. Frank DN, Feazel LM, Bessesen MT, Price CS, Janoff EN, Pace NR, et al. The human nasal microbiota and Staphylococcus aureus carriage. PLoS One. 2010;5:e10598.

49. Iwase T, Uehara Y, Shinji H, Tajima A, Seo H, Takada K, et al. Staphylococcus epidermidis Esp inhibits Staphylococcus aureus biofilm formation and nasal colonization. Nature. 2010;465:346-9.

50. Delisle AL. Activity of two Streptococcus mutans bacteriocins in the presence of saliva, levan, and dextran. Infect Immun. 1976;13:619-26.

51. Joklik WK, Willett HP, Amos BD, Wilfert CM. Flora normal e infecciones oportunistas. En: Joklik WK, Willet HP, Amos BD, Wilfert CM. Zinsser Microbiología. $20^{\mathrm{a}}$ edición. Buenos Aires: Editorial Médica Panamericana; 1994; p. 524-681.

52. Segata N, Haake SK, Mannon P, Lemon KP, Waldron L, Gevers D, et al. Composition of the adult digestive tract bacterial microbiome based on seven mouth surfaces, tonsils, throat and stool samples. Genome Biol. 2012;13:R42.

53. Lamont RF, Sobel JD, Akins RA, Hassan SS, Chaiworapongsa T, Kusanovic JP, et al. The vaginal microbiome: New information about genital tract flora using molecular based techniques. BJOG. 2011;118:533-49.

54. Brotman RM. Vaginal microbiome and sexually transmitted infections: An epidemiologic perspective. J Clin Invest. 2011;121:4610-7.

55. Randelovic G, Mladenovic V, Ristic L, Otasevic S, Brankovic S, Mladenovic-Antic S, et al. Microbiological aspects of vulvovaginitis in prepubertal girls. Eur J Pediatr. 2012;171:1203-8.

56. Linhares IM, Giraldo PC, Baracat EC. New findings about vaginal bacterial flora. Rev Assoc Med Bras. 2010;56:370-4.

57. Fierer N, Hamady M, Lauber CL, Knight R. The influence of sex, handedness, and washing on the diversity of hand surface bacteria. Proc Natl Acad Sci USA. 2008;105:17994-9.

58. Dao H Jr, Kazin RA. Gender differences in skin: A review of the literature. Gend Med. 2007;4:308-28.

59. Holland KT, Bojar RA. Cosmetics: What is their influence on the skin microflora? Am J Clin Dermatol. 2002;3:445-9.

6o. Staudinger T, Pipal A, Redl B. Molecular analysis of the prevalent microbiota of human male and female forehead skin compared to forearm skin and the influence of make-up. J Appl Microbiol. 2011;110:1381-9.

61. Domínguez-Bello MG, Costello EK, Contreras M, Magris M, Hidalgo G, Fierer N, et al. Delivery mode shapes the acquisition and structure of the initial microbiota across multiple body habitats in newborns. Proc Natl Acad Sci USA. 2010;107:11971-5.
62. Gao Z, Tseng CH, Pei Z, Blaser MJ. Molecular analysis of human forearm superficial skin bacterial biota. Proc Natl Acad Sci USA. 2007;104:2927-32.

63. Capone KA, Dowd SE, Stamatas GN, Nikolovski J. Diversity of the human skin microbiome early in life. J Invest Dermatol. 2011;131:2026-32.

64. Elias PM. The skin barrier as an innate immune element. Semin Immunopathol. 2007;29:3-14.

65. Choi EH, Demerjian M, Crumrine D, Brown BE, Mauro T, Elias PM, et al. Glucocorticoid blockade reverses psychological stressinduced abnormalities in epidermal structure and function. Am J Physiol Regul Integr Comp Physiol. 2006;291:R1657-62.

66. Bibel DJ, Aly R, Shinefield HR. Antimicrobial activity of sphingosines. J Invest Dermatol. 1992;98:269-73.

67. Krishna S, Miller LS. Host-pathogen interactions between the skin and Staphylococcus aureus. Curr Opin Microbiol. 2012;15:28-35.

68. Zomorodian K, Mirhendi H, Tarazooie B, Zeraati H, Hallaji Z, Balighi K. Distribution of Malassezia species in patients with psoriasis and healthy individuals in Tehran, Iran. J Cutan Pathol. 2008;35:1027-31.

69. Ong PY, Ohtake T, Brandt C, Strickland I, Boguniewicz M, Ganz T, et al. Endogenous antimicrobial peptides and skin infections in atopic dermatitis. N Engl J Med. 2002;347:1151-60.

70. Fahlén A, Engstrand L, Baker BS, Powles A, Fry L. Comparison of bacterial microbiota in skin biopsies from normal and psoriatic skin. Arch Dermatol Res. 2012;304:15-22.

71. Taylor M, González M, Porter R. Pathways to inflammation: Acne pathophysiology. Eur J Dermatol. 2011;21:323-33.

72. Chronnell CM, Ghali LR, Ali RS, Quinn AG, Holland DB, Bull JJ, et al. Human betadefensin-1 and -2 expression in human pilosebaceous units: Upregulation in acne vulgaris lesions. J Invest Dermatol. 2001;117:1120-5.

73. Yamasaki K, Di Nardo A, Bardan A, Murakami M, Ohtake T, Coda $A$, et al. Increased serine protease activity and cathelicidin promotes skin inflammation in rosacea. Nat Med. 2007;13:975-80.

74. Miller M, Cook HA, Furuya EY, Bhat M, Lee MH, Vavagiakis P, et al. Staphylococcus aureus in the community: Colonization versus infection. PLoS One. 2009;4:e6708.

75. Wichmann K, Uter W, Weiss J, Breuer K, Heratizadeh A, Mai U, et al. Isolation of alpha-toxin-producing Staphylococcus aureus from the skin of highly sensitized adult patients with severe atopic dermatitis. Br J Dermatol. 2009;161:300-5.

76. Ong PY, Leung DY. The infectious aspects of atopic dermatitis. Immunol Allergy Clin North Am. 2010;30:309-21.

77. Sugita T, Tajima M, Amaya M, Tsuboi R, Nishikawa A. Genotype analysis of Malassezia restricta as the major cutaneous flora in patients with atopic dermatitis and healthy subjects. Microbiol Immunol. 2004;48:755-9.

78. Schwartz JR, Messenger AG, Tosti A, Todd G, Hordinsky M, Hay RJ, et al. A comprehensive pathophysiology of dandruff and seborrheic dermatitis -towards a more precise definition of scalp health. Acta Derm Venereol. 2013;93:131-7. 